\title{
¿Vindicando al charnego? El discurso autobiográfico de Javier Pérez Andújar y Jorge Javier Vázquez
}

\author{
Vindicating the Charnego? Classim and segregation \\ in Javier Pérez Andújar's and Jorge Javier Vázquez's \\ autobiographical discourse
}

\author{
Mikel Aramburu \\ Departament d'Antropologia Social \\ Universitat de Barcelona \\ mikel.aramburu@ub.edu
}

\section{RESUMEN}

En este artículo analizo dos relatos autobiográficos publicados recientemente por hijos de inmigrantes procedentes del sur de España y radicados en Cataluña. Javier Pérez Andújar (2011) en Paseos con mi madre y Jorge Javier Vázquez (2013) en La vida iba en serio tematizan su condición social como jóvenes de las periferias urbanas presentando un discurso que, contado en primera persona, es inédito en el panorama catalán. Su relevancia deriva de una serie de factores. Primero porque conforman una nueva voz que emerge en un vacío de autorrepresentaciones de este sector social. Segundo porque problematizan conflictivamente un lugar social que en el discurso hegemónico se había dado por "normalizado" y superado. Finalmente, aunque ambos reflexionan sobre sus orígenes migratorios y su difícil encaje en la mesocracia catalana, la condición migratoria originaria apenas se expresa en términos étnicos o nacionales; está en gran parte subsumida en la experiencia de la segregación urbana.

Palabras clave: Charnego; Autobiografía; Segunda generación; Clasismo; Segregación urbana; Nacionalismo catalán.

\section{SUMMARY}

In this article I analyse two autobiographical narrations that have recently been published by the sons of southern Spanish migrants to Catalonia. In Paseos con mi madre by Javier Pérez Andújar (2011), and La vida iba en serio by Jorge Javier Vázquez (2013), the authors deal with their social condition as youngsters in the urban periphery, producing a discourse, written in the first person, that is unprecedented in the Catalan context. The relevance of these books derives from a number of factors. First, they offer a new voice that rises out of a self-representation vacuum in this social sector. Secondly, they conflictively rethink a social place which hegemonic discourse had assumed "normalized" and overcome. Thirdly, although both reflect on their migratory origin and the difficulty of fitting into Catalonia's urban mesocracy, their migratory background is largely subsumed in the experience of urban segregation, and hardly expressed at all in either ethnic or national terms.

Key words: Charnego; Autobiography; Second Generation; Classism; Urban Segregation; Catalan Nationalism. 


\section{INTRODUCCIÓN}

En este artículo analizo cómo Javier Pérez Andújar en Paseos con mi madre (2011) y Jorge Javier Vázquez en La vida iba en serio (2013) escriben sobre sus orígenes sociales como jóvenes de las periferias urbanas de Barcelona, evocando una marginalización social donde confluyen sus orígenes foráneos y la experiencia vivida del clasismo y la segregación urbana. No nos interesa tanto la verdad histórica de los hechos narrados como la verdad subjetiva, la construcción de sí mismos como sujetos sociales a través del relato autobiográfico. Como señalan Smith y Watson (2001: 527) "People tell stories of their lives through the cultural scripts available to them, and they are governed by cultural structures about self-presentation in public". Comprender los cultural scripts de los relatos autobiográficos analizados requiere una contextualización histórica que en este caso debe remontarse a la cuestión de la inmigración española en Cataluña durante la Transición y su evolución posterior.

Durante la transición democrática, la relación entre inmigración e identidad catalana ocupó un lugar central en el debate público. Las dos principales fuerzas políticas del momento, convergentes y obrerismo de izquierda, forjaron un amplio consenso en torno a la catalanidad, no sin muchas dosis de ambigüedad.

Si para el nacionalismo catalán conservador de antes de la guerra la identidad nacional descansaba básicamente sobre la cultura y la lengua (Conversi 1997), cuando no en la descendencia consanguínea, según una influyente concepción racialista de la catalanidad (Vandellós [1933]2011), hacia finales del Franquismo fue emergiendo una posición más ambivalente sobre la catalanidad. Sin duda, la figura más importante de este cambio fue Jordi Pujol. En Immigració: problema i esperança de Catalunya (1976), al lado de una posición inequívocamente asimilacionista, que planteaba inscribir la cultura catalana sobre el inmigrante, concebido cual tabula rasa, Pujol se abría a una visión más cívica de la catalanidad, expresada en la fórmula que hasta hoy ha definido formalmente la identidad catalana: 'es catalán todo el que viva y trabaje en Cataluña, y quiera serlo'. Este giro hacia el ius solis era necesario para garantizar el futuro de la nación, la mitad de cuya población difícilmente se podía reconocer en los criterios de identidad (la consanguinidad y la lengua) que hasta entonces había manejado el catalanismo conservador. No obstante, para Pujol y gran parte del catalanismo, la catalanidad cívica era un compás de espera hacia la "catalanidad plena" (es decir, étnica) que se manifestaba especialmente en el uso de la lengua catalana. Pujol incluso llegaba a cuantificar la lengua como un $770 \%$ u $80 \%$ de la identidad catalana" (en Fernández 2009: 91). La ambigüedad entre catalanismo cívico y étnico tanto en la doctrina como en la obra de gobierno del catalanismo ha sido ampliamente notada (Shafir 1995; Vilarós 2003; Clua 2011; Domingo 2014). En todo caso, Pujol (1976), igual que otros observadores del momento (Esteva 1973; Solé 1982), creía que la adscripción voluntaria de la identidad catalana y la ulterior adquisición de la lengua catalana por parte de los inmigrantes venía favorecida por el deseo de ascenso social, lo cual hacía de la movilidad social condición necesaria de la catalanización de los trabajadores inmigrados.

Por su parte, la intelligentsia de los movimientos obreristas no sólo evitó una lectura etnicista de la lucha de clases, sino que asumió las reivindicaciones catalanistas en materia de autogobierno, lengua e identidad nacional (Solé 1982; Conversi 1997; 
Shafir 1995). Como notaba Candel (1985: 193): "La penetración de la inmigración en el hecho catalán se ha dado gracias a los partidos de la izquierda catalana (...) El inmigrante en estos partidos, más que comprender, lo que ha hecho es obedecer y ser disciplinado" (véase también López Bulla 1996: 172). Candel, de hecho, fue una pieza clave por el lado de la izquierda en forjar el consenso sobre la catalanidad durante la Transición. En el muy influyente Els altres catalans (1964), había planteado por primera vez la posibilidad de sentirse catalán sin ser de origen catalán ni hablar catalán, simplemente por vivir en Cataluña. Aunque Candel era menos equívoco que Pujol sobre la dimensión cívica de la catalanidad, también planteaba, y de ahí la admiración pujoliana por su persona, que la tierra de acogida, más que la de procedencia, era donde radicaban la identidad y lealtad primordiales del inmigrante. La idea de que la clase obrera no se podía fraccionar por el origen o la lengua y la noción de que todos los residentes en Cataluña, independientemente de su origen y cultura (e implícitamente de clase), formaban "un sol poble" continúan siendo ideas ampliamente aceptadas por los movimientos izquierdistas.

ERC, que durante la Transición profesaba un catalanismo etnicista a la vieja usanza, sería atraída al consenso a finales de los 90 (Fernández 2009). Por su parte, las voces de corte españolista, expresadas en diversos manifiestos de intelectuales, que planteaban la existencia de varias comunidades lingüísticas o culturales en Cataluña, se expresaban desde posiciones más bien alejadas de la experiencia de los trabajadores inmigrados y tenían poco predicamento entre ellos. Dentro del espacio hegemónico del catalanismo, la acusación de "lerrouxismo" (en referencia a la estrategia de Alejando Lerroux de explotar el descontento de los trabajadores inmigrantes contra la burguesía catalana y el catalanismo) ha sido un término que en el debate político contemporáneo se ha usado para acusar a quienes usan políticamente (incluso a quienes hacen mera referencia a) la correlación entre lengua y clase social, de crear divisorias sociales inexistentes o ya superadas y poner en riesgo la convivencia y la unidad de la nación catalana. Para que esta lectura tuviera éxito era necesario que la inmigración peninsular desapareciera del escrutinio público, escrutinio incómodo de realizar en tanto que el mero hecho de plantearlo como algo a ser pensado ya era sospechoso de intentar crear lo que por definición no existía ${ }^{1}$.

En los años 70 y 80, los estudios sobre la inmigración en Cataluña habían sido abundantes y en ellos el problemático mantenimiento de la identidad catalana era el tema central (Domingo 2014: 143). La "crisis del petróleo", que afectó principalmente a los barrios de inmigrantes, supuso un motivo de preocupación para el catalanismo. La fuerte segregación de barrios que no sólo estaban separados de los signos de autorreconocimiento de la ciudad y de la nación, sino gravemente discriminados en los servicios y las infraestructuras urbanas, hacía que los inmigrados, como señalaba Vázquez Montalbán (en Solé 1982: 10), "no estén en condiciones de emplear su tiempo libre para saltar la muralla e irse al encuentro de la Cataluña establecida", lo cual auguraba los peores presagios para el relato de la catalanización de esta población (Montes 1980; Botey 1986; Candel 1985).

\footnotetext{
${ }^{1}$ Los escasos estudios recientes que han cruzado las clases sociales y los usos lingüísticos (Alarcón 2005, Subirats 2012), muestran cómo la realidad laboral sigue expresando una acusada estratificación sociolingüística.
} 
La intensa segregación urbana ponía en peligro la integración de las segundas y terceras generaciones, de las cuales se había esperado, "en un natural devenir de los acontecimientos" (Candel 1964: 287), que culminaran el proceso de asimilación (véase también Solé 1981: 376-81). Sin embargo, a mediados de los 80, Candel ya no habla de una "natural" asimilación, sino de una peculiar acomodación de las segundas generaciones que él llamaba "acatalanas".

Sí, se sienten [catalanes]. Y más que sentirse, lo son. No pueden ser de ningún otro lado. Pero lo son sin el 'rollo' de la magnificencia y, todavía menos, de la mistificación. Y, lógicamente, se enfadan ante la duda de su catalanidad, una catalanidad atípica que puede parecer apática, una catalanidad que para ellos es como una cosa resuelta y arrinconada, con escasos matices de discusión (...) Con ellos, con la generación 'acatalana', acaba la historia de la inmigración en Cataluña (Candel 1985: 272).

Contra lo que pudiera parecer, la "acatalanidad" de la segunda generación no es para Candel una negación de Cataluña, sino una catalanidad administrativa, desmistificada. Si bien "no pueden mitificar los pueblos que sus padres dejaron", de Cataluña "Solo conocen la marginalidad, una Cataluña extraña, la Cataluña metropolitana" (ibid:: 271).

El análisis de Candel es especialmente relevante porque hasta entonces la mayoría de observadores había entendido la identidad de los hijos de inmigrantes como un juego étnico de suma cero, donde la ciudad y la nación catalanizaban por un lado y la familia y el barrio castellanizaban por el otro² (Esteva 1973; Solé 1981; Botey 1986). Si todavía no eran catalanes del todo era porque 'aún' les pesaba la herencia familiar y el entorno barrial. Candel en cambio, apunta a un proceso de diferenciación que no emana de su herencia étnica, sino que resulta de su acomodación a la tierra de acogida, adelantándose así a lo que Alejandro Portes y Rubén Rumbaut (2000) descubrirán en los Estados Unidos sobre las identidades "made in USA" de las segundas generaciones.

En cualquier caso, a partir de los años 90, la población de origen español en Cataluña desapareció del foco de las ciencias sociales catalanas. Con alguna excepción (Fernández 2006, 2009), apenas autores extranjeros estudian el tema (Woolard 1989; Cardoso 1995; Shafir 1995; Conversi 1997; Miley 2006). El crecimiento económico retomaba la visión optimista de los años 60, según la cual el tiempo corría a favor de la movilidad social ascendente y por tanto de la nativización de los migrantes y sus descendientes (Cardoso 1995; Conversi 1997). La alterización despectiva del castellanohablante de clase obrera, sintetizado en el uso de términos como xarnegos, castellans, patxecs, etc., fue cayendo en desuso (Prat 2007; Clua 2011, 2014). Por la parte inmigrante aparecería una voluntad de identificación con los nativos y con la tierra donde habían encontrado las oportunidades que en su lugar de origen no habían tenido (Solé 1982; Cardoso 1995; Conversi 1997). Además, la irrupción de nuevos 'otros' (los inmigrantes extranjeros) suscita un aluvión de trabajos de investigación (donde, por cierto, su relación con la cuestión nacional catalana será una cuestión muy marginal) y a partir de los años 90 el propio término 'inmigrante' sólo se aplica ya a los inmigrantes extracomunitarios.

\footnotetext{
${ }^{2}$ Con relación al campo político, Miquel Fernández (2006: 440) señala el mismo marco étnico de identificación: «los que vivían en estos barrio no eran 'pobres' o 'excluidos', no tenían 'menos oportunidades por el hecho de haber nacido allá'... sino que eran la comunidad 'andaluza' o 'extremeña"... en Cataluña”.
} 
Con el nuevo milenio, la inmigración española es algo que ya sólo parece interesar en pretérito a los historiadores que estudian el Franquismo y la Transición (Vilarós 2003; Marín 2009; Molinero e Ysas 2010). Con ocasión de la elección de José Montilla como presidente de la Generalitat, y espoleados por unas declaraciones previas de Jordi Sevilla en las que había asegurado que tal posibilidad "era demasiado pronto para un charnego", los periodistas Farràs y Cullell (2009) publican un libro titulado $L^{\prime}$ ascensor. L'arribada al poder dels altres catalans (subtitulo traducido en la edición castellana como "Charnegos al poder"). Cuando parecía que cualquier especificidad de esta población ya se había desvanecido, ésta reaparece pero sólo para poner en evidencia su integración; la elección de Montilla rubricaba este proceso ${ }^{3}$.

\section{DEL SILENCIO SOBRE LOS ORÍGENES AL “CHARNEGO POWER"}

A la impresión de que la integración de la inmigración española es algo superado, resuelto, no problemático, puede haber contribuido también el silencio de los propios inmigrados sobre su propia experiencia. En todo el siglo XX, apenas tres autores han publicado relatos autobiográficos como inmigrantes en Cataluña. Muchas obras de Candel tienen una dimensión autobiográfica en tanto que sus reflexiones y observaciones se alimentan en primer lugar de sus propias vivencias. Además de Candel, Memorias andaluzas (1980), de Paco Montes, y Cuando hice las maletas (1996), de José Luis López Bulla, también ofrecen crónicas de la inmigración a partir de experiencias vividas por los autores. Este tipo de relatos autobiográficos entran dentro del subgénero Memoir, donde, como señala Lee Quinby (1992: 299) el "yo" emerge a partir del diálogo con los otros, que son el objeto de atención prioritaria.

La escasez de autorrepresentaciones literarias de los inmigrantes peninsulares, o incluso la poca frecuencia con que la migración española ha servido como topos literario en la literatura catalana ${ }^{4}$ contrasta con la proliferación de relatos autobiográficos de inmigrantes de origen extranjero en Cataluña; Domingo (2015: 30-32) documenta

\footnotetext{
${ }^{3}$ En sentido similar, Teresa Vilarós (2003: 244-245) señala: "the former xarnegos are not only xarnegos no more, but as a social group they form the most astonishing succes stroy in their lightsepeed assimilation to Catalan culture and language as well as their upward economic status".

${ }^{4}$ El tema de la inserción social urbana de los migrantes procedentes del sur de España ha ido apareciendo esporádicamente en las obras de ficción. Dentro de la cinematografía cabría señalar desde Los Tarantos (1963) de Francesc Robira-Beleta y La Piel quemada (1968) de Josep Maria Forn hasta la más recientes Tapas (2005) de José Corbacho o Yo soy la Juani (2006) de Bigas Luna, pasando por el prolífico género del "cine quinqui" de finales de los 70 y principios de los 80. Entre la ficción literaria, con alguna excepción, como Carrer Bolivia (1999) de Maria Barbal o el autobiográfico Els castellans de Jordi Puntí (2011), el tema ha sido tratado sobre todo en la literatura catalana escrita en castellano, como Los alegres muchachos de Atzavara (1987) de Vázquez Montalbán o Un calor tan cercano (1998) de Maruja Torres. Pero han sido sobre todo las novelas de Juan Marsé las que han tratado el tema recurrentemente. En Últimas tardes con Teresa (1966), La oscura historia de la prima Montse (1970) o El amante bilingüe (1990), la mirada irónica y descarnada de Marsé ofrece una trama bastante similar en la que, con diferentes grados y matices, un ambicioso hombre pobre y sureño se vale del engaño para seducir a una joven catalana de clase media-alta, la cual, en una mezcla de redención solidaria y deseo sexual, se ve atraída por su exotismo y salvajismo meridional.
} 
al menos una docena de títulos aparecidos entre 2004 y 2013. Este autor (2014: 303) denomina "silencio sobre los orígenes" a la escasez de autorrepresentaciones de los migrantes peninsulares en Cataluña. Un silencio roto en escasas ocasiones y no sin cierto estímulo externo. En los tres casos mencionados arriba destaca el impulso del intelectual catalán que les anima a escribir sobre su experiencia como migrantes (Josep Benet en el caso de Candel, Joaquim Molas en el caso de Montes, y Xavier Folch en el caso de López Bulla).

¿Cómo podemos interpretar el silencio sobre los orígenes? ¿Se trata de que la experiencia de estas personas, diluidas ya en la sociedad de acogida, no reviste de ningún interés digno de ser contado? O ¿podríamos hablar de un "pacto de silencio". Tal y como interpreta Gérard Noirel (1988: 238) el silencio de franceses e inmigrantes europeos sobre el pasado migratorio de Francia? "Es como si un pacto tácito se hubiese firmado donde cada uno ha encontrado su propio beneficio". Por un lado, una identidad nacional que hurta el papel de las aportaciones migratorias a la formación de la nación imaginada, por otro lado, un pasado vergonzante que es mejor no hacer público y a ser posible olvidar.

Son varios los autores que se refieren a un silencio autoimpuesto. En su libro de entrevistas a inmigrantes de L'Hospitalet, Botey (1986: 12) señalaba que "en bastantes casos el entrevistado había de esforzarse por recordar los hechos de su vida pasada. No por falta de memoria, sino porque había habido una explícita voluntad de olvidar aquella época". Luis Miguel Narbona (2014: 63) recuerda que mientras recogía historias de inmigrantes en el Baix Llobretgat durante los años 80, le relataban que las deportaciones y las detenciones en centros de internamiento de inmigrantes habían sido moneda corriente en la Barcelona de los años 50, "pero me sorprendió que, según reconocían, no habían hablado del hecho (ni tan solo a la familia) hasta que me lo explicaron a mí, prueba del choque vivido". José Luis López Bulla, autor de una de las autobiografías mencionadas y que fue secretario general de CCOO de Cataluña entre 1976 y 1995, señala sobre esto:

Es curioso como hay mucha gente [inmigrada], todavía hoy, que se resiste a explicar su experiencia personal, su aventura. Es una manera de hacer muy similar a la que tienen muchas personas que no quieren hablar de lo que vivieron en la Guerra Civil. Con el peligro de quedarse con un país sin memoria, como si haber sufrido una contienda bélica o haber emigrado fuese algo vergonzante (Farràs y Cullell 2009: 136)

El paralelismo que establece López Bulla (también notado por Juanjo Pujadas 2014: 44) entre el olvido del proceso migratorio peninsular y la traumática experiencia de la guerra civil puede parecer extremo, pero puede tener cierta utilidad teórica ${ }^{5}$. El silencio sobre la Guerra Civil no es sólo la ocultación de un pasado vergonzante sino

\footnotetext{
${ }^{5}$ Apuntar la carencia relativa de autorepresentaciones por parte de los inmigrantes peninsulares en Cataluña puede entrar en contradicción con la existencia, creciente según algunos autores (Solé, 1982, López Bulla 1996), de expresiones nostálgicas del folclore de origen. Fernández $(2006,2009)$ que ha estudiado estos procesos con detenimiento, señala incluso que esas actividades han sido alimentadas por los partidos políticos gobernantes (CiU y PSC) para cultivar el clientelismo político. Con todo, una política de reconocimiento de la diversidad cultural no equivale a una política de reconocimiento del origen migratorio como hecho sociopolítico. De hecho, como parece apuntar Fernández, el cultivo de la primera puede haber ido en detrimento de la segunda.
} 
el silenciamiento de la memoria (al menos en la esfera pública) en aras de la preservación de la convivencia (Rodrigo 2006). "Pacto de silencio" es cómo ha sido llamado en los estudios sobre la memoria de la guerra civil y de la represión de la posguerra el hecho de erigir, durante la Transición, la convivencia precisamente sobre el olvido. Será la "generación de los nietos de los vencidos la que no parece aceptar el pasado de la Guerra Civil como algo sobre lo que es mejor 'no hablar, no pensar'" (Rodrigo 2006, Ferrándiz 2008).

En el caso de la migración peninsular en Cataluña parece que también habrá que esperar a la emergencia de una generación de autores (en este caso "los hijos") que se puedan reconocer públicamente como ligados a la inmigración familiar. Los relatos autobiográficos de Javier Pérez Andújar (2011) y Jorge Javier Vázquez (2013) que analizaremos aquí han sido los primeros en asumir esta voz.

Las obras consideradas deben ser contextualizadas dentro de un proceso de resignificación del "charnego" ocurrido en los últimos años. Según los diccionarios 6 , "charnego" es un término despectivo que designa a los castellanohablantes de origen inmigrante en Cataluña, pero su uso social siempre ha tenido una clara connotación clasista (Candel 1964, 1985; Prat 2007; Clua 2011). "Con el tiempo", señalaba López Bulla (1996: 92), "he llegado a saber que jamás se llama charnego a quien sabe la diferencia entre el dórico y el corintio». Barrera (1985) señala que además de las connotaciones clasistas, la imaginaria del charnego (en la Cataluña interior de los años 80 que él estudió) remitía también a mestizaje o bastardía, lo cual guarda relación con el origen etimológico de la palabra (hijo de catalán y francesa). "El charnego no es ni catalán ni castellano, apuntan varios de los informantes, no es de aquí ni de allá; se encuentra en una desazonadora posición heterodoxa, marginal, ambigua, liminal... y por tanto potencialmente peligrosa" (1985: 448).

Sin embargo, como suele ocurrir con este tipo de términos peyorativos, los sujetos afectados pueden acabar convirtiendo el estigma en motivo de orgullo. Aunque también habría que señalar a Candel como pionero en hacer del "charnego" un término de autorreconocimiento, ha sido el periodista Guillem Martínez (2001, 2002) quien ha popularizado el término "charnego power", término que acuñó precisamente con ocasión de la publicación de Catalanes todos (2002) de Javier Pérez Andujar, donde este autor hace un retrato ácido de la connivencia de buena parte de la elite catalana con el régimen franquista. El "charnego power" es una expresión que han ido haciendo suya diversos hijos de la inmigración, profesionales de la cultura en su mayoría, como Andreu Buenafuente, Jordi Évole o José Corbacho, haciendo referencia con ello a una reivindicación orgullosa no tanto del origen foráneo y de una cultura y una lengua exterior a la catalanidad, sino de una condición social híbrida y mestiza alérgica a cualquier guerra identitaria. Pero el sentido que otorga Martínez a la expresión designa sobre todo una periferización social que aporta "un punto de vista diferente" que pone bajo sospecha el orden de las cosas. El "charnego power" de Martínez es en cierta manera lo que el "marginal man" era para Park ([1928] 2000), o la figura del "extranjero" para Simmel ([1908] 2012), es decir, no tanto un sujeto marginalizado ni una alteridad cultural, sino un punto de vista que por su misma exterioridad resultaba crítico, creativo, y perturbador.

\footnotetext{
${ }^{6}$ Véanse, diccionario de la RAE (http://dle.rae.es/?id=8d3XHaZ), diccionario de la Enciclopedia Catalana (http://www.enciclopedia.cat/search/site/xarnego).
} 
Otro indicador de una nueva visibilización y vindicación de la condición charnega es la emergencia pública de los castellanohablantes independentistas, como la asociación "Súmate", una entidad soberanista que se autodefine como ligada a la inmigración española y que usa públicamente el castellano en sus intervenciones públicas, lo que implica una ruptura de la etiqueta lingüística dominante. La novedad no es que migrantes peninsulares o descendientes suyos sean independentistas, un fenómeno que Vandellos [1933] 2011) ya notaba en los años 30, sino que lo hagan desde una reivindicación pública y orgullosa de sus orígenes.

La resignificación de la figura del charnego guarda relación con lo que diversos autores han señalado para otros contextos sobre el tránsito, entre la primera y las siguientes generaciones, hacia una mayor reivindicación de los orígenes migratorios (Noriel 1988; Portes y Rumbaut 2000; Levitt y Waters 2001). Aunque es difícil generalizar, en la primera generación, y aún en la segunda, la estrategia adaptativa favorece la autodesvalorización y la asimilación, mientras que las siguientes generaciones se abren a la reivindicación de los orígenes cuyos padres hicieron todo por olvidar. El viraje a partir de los años 80 hacia marcos políticos más multiculturales también ha favorecido este proceso. Pero, a diferencia de lo que cuentan estos autores, lo que muestra la nueva voz que analizaremos aquí no apunta a una reetnificación ni a una reinvención idílica de los orígenes.

\section{VIDAS PARALELAS, RELATOS CRUZADOS}

Las vidas de Javier Pérez Andújar y Jorge Javier Vázquez tienen mucho en común. Los dos autores son de la misma generación, apenas 5 años les separan, y por tanto sus relatos cubren una misma época, la de su juventud en los años 80 y 90. Ambos son hijos de inmigrantes del sur de España que llegaron a Cataluña en los 60. Ambos relatan ciertos paralelismos biográficos sorprendentes: Los dos trabajaron como reponedores en el mismo supermercado mientras estudiaban la misma carrera en la misma universidad (Filología hispánica en la Universidad de Barcelona), experiencia universitaria que, por otra parte, brilla por su ausencia en ambos relatos, que transitan sin transición de la vida en el barrio a los primeras aventuras profesionales en Barcelona y Madrid. Los dos son hijos de obreros industriales izquierdistas y se criaron en polígonos de viviendas, en barrios colindantes del mismo lado de la periferia metropolitana: Pérez Andújar en Sant Adrià del Bessos, Vázquez en el barrio de Sant Roc de Badalona. Ambos harán caso omiso de los nombres oficiales y hablarán de San Adrián y San Roque, como hacen los naturales de estos lugares. Ambos revisitan su vida en estos barrios cuando han reconstruido su vida fuera de los mismos como profesionales de éxito en el mundo de la cultura. Pérez Andújar es un reconocido escritor y periodista, premiado en 2014 con el Premi Ciutat de Barcelona de periodismo. Vázquez es un célebre presentador de televisión de "género rosa", galardonado con el Premio Ondas en 2010.

Los dos trazan una reflexión sobre sí mismos como sujetos social y geográficamente determinados, constituidos por una segregación que ante todo es urbana, espacial, y en cuya idiosincrasia los factores étnicos e incluso de clase quedan subsumidos. Ambos elaboran un relato sobre sus orígenes sociales que oscila todo el rato entre la familiaridad y el extrañamiento, el distanciamiento y la reconciliación. 
Aun así, son dos libros muy diferentes en enfoque y estilo. Lo primero que llama la atención del elaborado estilo de Pérez Andújar en Paseos con mi madre, es su peculiar forma de hablar del pasado usando alternadamente el futuro simple y el futuro continuo. Como su admirado Francisco Umbral, hace un uso ingenioso y lírico del idioma, rindiendo homenaje al argot juvenil de una época (con su "pasma", "papela", "levantar", "peña", "chapar"), combinando acidez y ternura a partes iguales y recurriendo con frecuencia a hipérboles que subrayan la intensidad expresiva.

Se ha dicho de Jorge Javier Vázquez que ha revolucionado el lenguaje televisivo (él mismo ha señalado que mostrar los bastidores del plató en sus programas guarda relación con la falta de espacio en la casa de su infancia) pero literariamente es menos innovador, y la crítica literaria se ha ensañado con él. Mezcla expresiones castizas con secuencias de sexo explícito y expresiones "tenidas por vulgares o soeces", que es como el diccionario define la voz "barriobajera" ("era de un hijoputismo extremo", "estoy hasta el coño", "me callé como una puta", etc.). Con todo, los méritos literarios de una u otra obra es lo que menos nos interesa aquí.

Los enfoques de estos relatos autobiográficos son también marcadamente diferentes. Pérez Andújar hace una crónica de los barrios periféricos de la Barcelona metropolitana a través de la cual emergen numerosos detalles autobiográficos, pero los aspectos más íntimos de la vida familiar se preservan de la mirada del lector. La perspectiva de Vázquez es casi la opuesta; se trata de una reflexión sobre su vida familiar que se explaya en amores y rencores, sin eludir los aspectos más íntimos de su vida corporal; es sin duda una "biografía incorporada" (Porzio 2012). En consecuencia, los loci donde se desarrollan las tramas también son diferentes. Para Pérez Andújar el protagonista de su libro son "los bloques", es decir los barrios periféricos, mientras que para Vázquez el escenario privilegiado es "el piso de cincuenta metros cuadrados" en el que vivía con su familia, es decir, la esfera privada.

Javier Pérez Andújar expone la vida pública de la periferia metropolitana. Su objeto no es solo su barrio (que ni siquiera se nombra) como los barrios obreros del Área Metropolitana de Barcelona en general. Por el libro desfilan crónicas de La Mina, Sant Cosme, Ciutat Meridiana, la Salut y Sant Roc, Bellvitge y el Gornal, con sus heroicas huelgas obreras y movilizaciones vecinales para conquistar equipamientos y servicios (el propio autor aparece secuestrando autobuses urbanos) los primeros ayuntamientos democráticos copados por comunistas y socialistas, barrios con sus "plazas rojas", sus calles Federico García Lorca, y su contracultura juvenil del rock y del comic. Su mirada es decididamente sociológica (de una sociología poética en cualquier caso). Las crónicas de los barrios le sirven para construir una categoría social: la Barcelona de los bloques y más allá de ella "la internacional de los bloques". Se suceden numerosas comparaciones que marcan cercanías y distancias identitarias y sentimentales: "De nuestra casa en San Adrià del Besos estaban más cerca los pisos de la M-30 de Madrid, las canastas de baloncesto y las vallas metálicas de Harlem (...) que el paseo de Gràcia o cualquier otra calle del centro de Barcelona" (2011: 19); "Viviré más cerca de Carabanchel que de las Ramblas porque a Carabanchel iré a cada rato con los discos de Leño, con las canciones de Rosendo, con sus ritmos rudimentarios, ásperos como cuando se pasa la mano por las paredes de un bloque"(Ibid.: 23). En este imaginario geográfico, los bloques actúan como metonimia de la clase social: "Antes de sentirme de ningún país, de ninguna patria o nación, voy a pertenecer a la internacional de los bloques" (ibid.: 107). 
Jorge Javier Vázquez en cambio se centra en la vida privada de su familia, y el barrio sólo adquiere protagonismo como contexto (eso sí, muy presente) de la vida personal y familiar. El libro es una mirada intimista e introspectiva sobre la colisión entre su homosexualidad y el entorno homófobo en el que vivió hasta que se fue a vivir a Madrid. Como en Pérez Andújar, la presentación de Vázquez resalta el obrerismo suburbial de sus orígenes, pero en este caso supeditado a un relato sobre la opresión a la que el entorno (la familia y el barrio) someten su sexualidad. Si Pérez Andújar escribe desde la subalternidad, Vázquez escribe desde el subalterno del subalterno. "El marica" del bloque es una minoría dentro de una minoría, en perpetua soledad hasta una edad muy tardía, primero enfrascado en una lucha interna para reprimir su deseo, después practicándolo clandestinamente, pero siempre temeroso del escarnio público.

La vida iba en serio ilumina elementos de la cultura popular suburbial ausentes en Paseos con mi madre. Ante la hostilidad masculina de la calle, Vázquez se refugia en el mundo de las mujeres, las chicas que lo defendían de las burlas de los chicos, las tardes que pasaba junto a su madre y una vecina para no tener que bajar a la calle. Aquí no hay huelgas obreras, ni movilizaciones vecinales, ni rock ni comics, pero sí la llegada semanal del Lecturas, codiciado por los miembros de toda la familia que tenían que respetar pequeños rituales de espera, o el espectáculo cotidiano de las peleas de vecinos, en torno a las cuales se arremolinaba la concurrencia ( nos dábamos codazos para estar lo más cerca posible de los contendientes y nos daba rabia que alguien interviniera para separarlos", señala premonitoriamente).

El contraste entre los dos autores se hace explícito cuando recrean las penalidades de la vida en los barrios durante su adolescencia. Por ejemplo, cuando hablan del desempleo durante la crisis de los 80, mientras que para Javier Pérez Andújar "todo San Adrián estaba en el paro" (2011: 114), para Jorge Javier Vázquez el desempleo solo aparece como una obsesión familiar: "Era uno de los temas preferidos de mi padre" (2013: 92).

Los dos hacen abundantes referencias a las condiciones de vida en los bloques, pero mientras Javier Pérez Andújar nos habla de barrios atravesados por ríos con "espumas y dioxinas", "nubes de cenizas", "centrales térmicas que chisporrotean" y, en general, "todo lo que nadie ha querido en Barcelona ni en ninguna otra parte" y que le conducen a un "ecologismo de clase" (2011: 69), Jorge Javier Vázquez nos habla de la incomodidad con que los cinco miembros de la familia convivían en la casa de "cincuenta metros cuadrados", el escenario ubicuo donde se suceden las anécdotas sobre el hacinamiento, la familiarización con las cucarachas ("los visitantes") o las escenas escatológicas del baño ("nada más abrir la puerta del baño, llegaba el olor al comedor"). El piso de cincuenta metros cuadrados es a Vázquez lo que los bloques a Pérez Andújar.

Pero más allá de estas diferencias de foco, los dos vienen a dar una noción muy similar sobre su condición social originaria.

\section{CRÓNICAS DEL DESARRAIGO}

Cuenta Pérez Andújar que en 1984, la noche en que Convergència i Unió consi- 
guió su primera mayoría absoluta, se cruzó con un grupo de "hombres encorbatados" que se dirigía al Hotel Majestic, donde la coalición reunía a su militancia en las noches electorales, y que oyó a uno de ellos exclamar: "Así aprenderá la charnegada". A lo que el autor interpone una de sus enigmáticas frases:

Pero los ó́dos con los que oigo el mundo me van a decir que los charnegos no existen, que sólo existen los bloques (y que los bloques son más de quienes los han hecho que de los que viven en ellos) (2011: 164-65).

Aunque no lo cita en ningún momento, estas palabras de Pérez Andújar pueden remontarse a Candel, quien a mediados de los 80 señalaba (1985: 267) que si todavía era posible hablar de "hijos de inmigrantes" era "por la influencia de un urbanismo de capital autóctono que especulaba con los metros cuadrados por persona". También como Candel, o como más tarde señalarán Comas y Pujadas (1991), que a contracorriente de las interpretaciones sociológicas en boga sugerían que de los barrios de inmigración emergía una condición social antes que una identidad étnica, para Pérez Andújar lo que podríamos llamar la "Condición charnega" remite más a la experiencia de estar excluido que a la oposición a la catalanidad.

El charnego no es alguien que habla castellano y que tiene problemas cósmicos con el catalán. Ser charnego es un ámbito social. Yo soy charnego. Ser charnego consiste en que no eres pariente de nadie ni has estudiado con nadie. No perteneces a la Casta del Mandarinato (en Martínez 2002)

Con todo, en diferentes escritos y entrevistas concedidas, Pérez Andújar se ha mostrado ambivalente sobre la existencia de algo así como una "condición charnega" En todo caso, ya se llame charnego o habitante de los bloques, de sus escritos emerge un sujeto social enclasado que antes que por su origen foráneo o por ser castellanohablante es definido por su posición subalterna. En la retórica de Pérez Andújar, el "Catalán" también suele ser un sujeto enclasado: "ser catalán consiste más en pertenecer a un estatus social que en pertenecer a un país" (2011: 105); "me dará vergüenza ser catalán como me da vergüenza ponerme corbata. Eso son cosas que no se hacían en mi casa" (ibid.: 106). Pérez Andujar maneja las identidades de una manera tan alejada del catalanismo cívico oficial ("es catalán todo el que vive y trabaja en Cataluña") como de su alternativa etnicista. Así, su amigo Ignasi, más que un catalán, es un vecino que habla una lengua diferente a la mayoritaria del barrio. Pérez Andújar de alguna manera descatalaniza a Ignasi cuando dice que su catalán híbrido y mestizo, con sus "nusaltrus", sus "buenu" y sus "allavorans" ha sido desautorizado y traicionado por la normalización lingüística necesaria para la nation building. "Cuando esa manera de hablar se desautorice [por la normalización lingüística] sentiré que han vuelto a ganar los pijos". El "nusaltrus" de su amigo Ignasi todavía forma parte de la «internacional de los bloques".

Mi castellano estará más cerca del 'nosaltrus' de los viejos [catalanes] de San Adrián que de los tribunales lingüísticos que otorgan el título de catalán. Va a estar más cerca mi

\footnotetext{
${ }^{7}$ Véase por ejemplo: "Con los charnegos pasa como con los monstruos de los sueños, que sólo existen en la cabeza de quien los nombra. Pero también están por todas partes porque son la gente" (Pérez Andújar, 2013: 20).
} 
castellano del "estógamo" y del "no sus vayáis" de mi familia, que de mi título de licenciatura en hispánicas (ibid:: 108).

Aunque lo estudió en la escuela y fue animado por su padre a aprender catalán, hablarlo lo sentirá como una impostación: "Hablar como ellos, a ratos lo habré deseado; pero me parecerá luego que eso es hacer trampas" (ibid.: 106). De manera similar, aunque el padre de Jorge Javier Vázquez, nacido en Badalona de padres murcianos, hablaba catalán y se "empeñaba" en que él lo hablara, igualmente dice que le "daba vergüenza" hacerlo. "Y además, por mucho que mi padre hablara catalán, no era como los padres que vivían en el centro. Le faltaba aplomo, seguridad, arrojo" (2013: 103).

Pérez Andújar desarrolla más que Vázquez una noción del no-catalán que, al igual que el "acatalán" de Candel, no es un concepto simétrico del catalán, pues se mueven en parámetros y coordenadas conceptuales diferentes. Lo no-catalán no es la oposición al catalán, como una identidad étnica o nacional alternativa. No llega a ser una afirmación de lo español, como ilustra la siguiente anécdota sobre un espectáculo de Manolo Escobar en un teatro del Paralelo al que fue acompañando a su madre. El público lo forma "gente mayor, obrera, que se arregla para ir al teatro". Esta gente, que se desgañita coreando Mi carro y El porrompompero, deja de hacerlo cuando el cantante, que vivió en Badalona, entona Y viva España.

A la concurrencia le da apuro corear el estribillo, quizá porque intuye algo raro, le da mal rollo, cree que eso no está del todo claro. Manolo Escobar también se da cuenta a la primera y deja de hacerle gestos al público para que le siga, así que termina la canción solo (2011: 174).

Lo no-catalán tampoco es lo andaluz, de cuyo folklore en tierras catalanas Pérez Andújar, hijo de padres andaluces, se desmarca con cajas destempladas, como cuando se mofa de los centros rocieros y de "los coros y danzas de la Feria de Abril", acontecimiento que fustiga por seguir «empecinada en su monserga de rumbas y sevillanas" ${ }^{8}$. Prolongando el "silencio sobre los orígenes" del que habla Domingo (2014), Pérez Andújar muestra la dificultad de construir su identidad sobre el reconocimiento del origen familiar.

Mi madre me va contando en estos paseos nuestros nuestro linaje granadino. Lo que ella sabe alcanza hasta cinco generaciones (...) Pero hay un precipicio que me separa de la genealogía que mi madre quiere transmitirme. Todo lo que explica ha ocurrido muy lejos, en otro paisaje, en una pequeña sierra de Granada. Es un lugar ficticio, porque lo real para nosotros han sido las fábricas de aquí, los bloques, los solares. De casi ninguna de las personas que va nombrando tengo más referencia que la de sus palabras (2011: 177).

Los migrantes y sus descendientes se definen, tanto en Pérez Andújar como en Vázquez, no a través de una identidad colectiva alternativa, sino a través de una dialéctica negativa, por la negación del ser ("la nada" llamaba Pérez Andújar a las periferias metropolitanas en una de sus recientes crónicas electorales en El País 15/09/2015), desprovistos de la asertividad necesaria para tener un estatuto ontológico independiente. Se definen ante todo por el "desarraigo", que es un término que ambos usan con frecuencia para hablar de su condición social originaria. El desarraigo, ya era un tema

${ }^{8}$ No le ocurre lo mismo con el flamenco, del cual da muestras, a lo largo del libro, de ser un ferviente seguidor. 
frecuente en la autorepresentación de los inmigrantes de primera generación ("¿cuándo empieza uno a no ser casi de ninguna parte?", se preguntaba López Bulla (1996: 33). Dolors Comas y Juanjo Pujadas (1991: 51), señalaban que sentirse forastero tanto en la sociedad de origen como en la sociedad de llegada constituía una "doble negación identitaria" que configuraba la "cara oscura de su ser existencial. El conflicto que podría generar esta doble extranjería

tiende a ser arrinconado, solapado, pasando por delante esa realidad sustantiva de la cotidianidad, la vida social de la pequeña comunidad, del barrio, que ellos sí han creado con su propio esfuerzo. El bario tiende a ser entonces el objetivo de su elaboración simbólica, constituye el epicentro de sus vidas. Se trata de la cara diurna y luminosa, que puede ser presentada en público, sublimándola (ibid.: 51)

El desarraigo sigue marcando a nuestros autores, si bien ahora los términos del desarraigo se desplazan de un horizonte regional o nacional a uno de geografía urbana, donde la pertenencia barrial resulta problematizada.

[En 1973] llevaba más de una década llegando gente a la ciudad en continuas oleadas, emigrantes que venían, que veníamos, de todas las partes de España (pero la verdad es que yo nací aquí y de esa incertidumbre trata este libro (Pérez Andújar 2011: 137).

La incertidumbre es que nació aquí, pero el "aquí" es el aquí de los bloques y ésta es una identidad problemática. Aunque "ser de barrio" es una idiosincrasia que reclaman ambos autores, designando con ello algo similar a lo que Bourdieu llamaba el "gusto de necesidad" (1988), un materialismo alejado de toda pretensión e idealismo, tampoco parecen encontrar en el barrio una identidad satisfactoria. Pérez Andújar lo explica así: "Andaré buscando entre los bloques, al pie de los edificios de todas las afueras unas raíces las mías que no agarrarán en ninguna clase de suelo (...) Ahora, lejos de mis bloques, sin haber sido capaz de pertenecer a ellos, me siento profundamente apátrida" (ibid:: 153).

El desarraigo también es protagonista de Jorge Javier Vázquez: "La mayoría de nosotros éramos hijos de padres desarraigados" (2013: 71). Pero aunque Vázquez desarrolla más que Pérez Andújar la apropiación del territorio como un sitio de pertenencia, el barrio tampoco es un lugar donde Vázquez se pueda reconocer fácilmente, no solo por estar formado por "bloques horribles y feos", sino por ser hostil con su sexualidad clandestina y sin embargo conocida. Al final, la sensación es, como en Javier Pérez Andújar, de un cierto estar entre dos mundos sin pertenecer a ninguno: "Lo peor era la sensación de no saber a qué mundo pertenecía, porque no encontraba compañeros en el bloque - era el único de mi edad que todavía seguía estudiando-, pero tampoco me sentía a gusto entre la gente que se movía por la ciudad" (Ibid.: 99).

El tema común de los dos autores es sin duda sentirse excluidos de la ciudad, la ciudad del centro, la ciudad mesocrática, la ciudad catalana, que ambos reifican al tiempo que representan como inaccesible.

\section{LA CIUDAD NO ES PARA TI}

Paseos con mi madre y La vida iba en serio constituyen una contranarrativa del discurso hegemónico de la integración de los migrantes peninsulares. A pesar de que 
las biografías de ambos autores se podrían esgrimir como ejemplos de chicos de suburbio convertidos en profesionales de éxito, para quienes el ascensor social ha funcionado, sus relatos están lejos de ser un agradecimiento por las oportunidades recibidas. Pérez Andújar simplemente elude hablar de sí mismo en una trayectoria ascendente (en todo caso habla en términos de un desplazamiento espacial que le resulta más bien incómodo: "me da apuro formar parte de Barcelona, dejar de ser de San Adrián" (2011: 125), y las consideraciones sobre el ascenso social en los barrios periféricos son bastante sarcásticas, como cuando habla de Ciutat Meridiana:

El ascensor funicular aún flamante, con el logo de la Generalitat, es lo más parecido que hay aquí al hipotético ascensor social de los sociólogos; pero adónde conduce ese ascensor es a la boca de metro, que espera hambrienta a la gente que va a echar horas con la ropa salpicada de yeso y pintura (ibid.: 56).

En cambio, en La vida iba en serio, el ascenso social de Jorge Javier, y a través suyo de su familia obrera, es omnipresente y triunfal (el autor se deleita en mostrar como él, el vergonzante marica de la familia, es el único hijo que hace realidad la obsesión del padre para que los hijos se labraran una carrera profesional a través del estudio), pero su triunfo profesional se produce en Madrid, quedando Cataluña al margen de los agradecimientos, y Barcelona ("aséptica y envarada") siempre muy mal parada en la comparación con Madrid ("más campechana").

Los relatos de ambos autores ponen el énfasis en una exclusión espacial que se remonta al hecho migratorio de los padres. Jorge Javier Vázquez señala que para los migrantes que llegaban a San Roque, el barrio, y no la ciudad ni Cataluña, se convertía "en su propia Estación Termini", el fin del trayecto (2013: 71). "Hablábamos de Badalona como quien habla de otra ciudad. Nuestra periferia conformaba un universo tan distinto del centro que vivíamos con la sensación de que no pertenecíamos a la ciudad" (ibid.: 94). Igualmente, para Javier Pérez Andujar, los barrios periféricos están compuestos por "gente que había venido a vivir a Barcelona y que no iba a pisar Barcelona en lustros, quizá en su vida" (2011: 20). Desde Sant Adrià, el centro de Barcelona aparece como un lugar lejano que se concretaba en la imagen brumosa de las torres de la Sagrada Familia.

Poco importa que la ciudad central sea social y lingüísticamente más heterogénea que lo que estas representaciones sugieren, el caso es que se trata de una divisoria sociogeográfica fuertemente instalada en el imaginario urbano. La distancia insalvable entre el barrio de inmigrantes y la ciudad central ya había sido un tema frecuente de la literatura sobre migración de los años 80. Los tropos del "barrio-ghetto" y la "muralla" que lo separaban de la ciudad están presentes en casi toda la literatura de la época (Montes 1980: 124; Solé 1982: 10; Botey 1986: 42; Candel 1985: 287; López Bulla 1996: 131). La novedad de los relatos autobiográficos que nos ocupan es que nunca antes (con la salvedad, tal vez, de los primeros libros de Candel) se había contado la experiencia de la segregación desde el otro lado de la muralla, y sobre todo que más que aislamiento étnico lo que enfatizan las nuevas autobiografías es una exclusión social $\sin$ ambages.

A mediados de los ochenta Badalona era una población profundamente clasista en la que comenzaba a vivirse cierta efervescencia nacionalista (....) Hablar en castellano suponía expresarse en una lengua invasora, y los catalanes lo utilizaban cuando querían hacer 
referencia a una persona que pertenecía a un estrato social inferior. Yo vivía en el barrio que tenía peor fama y hablaba castellano, así que estaba empezando a forjarse un mundo en el que yo no tenía cabida (Vázquez 2013: 99-100).

Para los vecinos de San Roque, el centro de Badalona era un mundo extraño y hostil. De adolescente, paseando con unos amigos por el centro de Badalona, le angustia tomar algo en el Antillana, "el bar de copas de los pijos", ante el temor "a que todas las miradas se volvieran hacia mi preguntándose qué coño hacía en su territorio uno de San Roque, que además no hablaba catalán. En Badalona, y en aquella zona, o eras pijo o no eras" (ibid:: 100).

En ambos libros se destaca la experiencia de la discriminación urbana, mostrando lo fácil que era en aquél momento (finales de los años 80) reconocer en el centro de la ciudad a los que venían de barrios periféricos, delatados por su vestimenta, postura corporal y lenguaje, así como la frecuencia con que eran discriminados, tratados como peces fuera del agua a los que había que devolver a su lugar.

En la plaza de la Catedral dos pasmas de uniforme marrón (...) van a pararme para pedirme la papela, y cuando me preguntan qué hago en Barcelona viviendo en San Adrián les enseñaré la carpeta de los apuntes, porque es verdad que uno siempre enseña lo mejor que tiene, y les voy a contestar que vengo de la universidad. Entonces, uno de los polis pone cara de pillo (...) y exclama queriendo pulverizar mi verdad con la verdad de su rutina: ¿y es que en San Adrián no hay universidad? (...) Así que de San Adrián del Besós... ¿Y se puede saber qué estás haciendo entonces en Barcelona? (Pérez Andújar 2011: 22)

Aquí es la Policía Nacional la encargada de preservar el orden social recordándole que está fuera de lugar. Tirando una vez más de hipérboles, Pérez Andújar se sirve de la escena de la detención ("humillación") del Vaquilla ("un chaval de barrio") para concluir: "no había manera de sentirte de Barcelona, porque sabíamos que acercarse allí, a la Diagonal, sólo llevaba a que le machacaran a uno la cabeza".

El escenario que plantea Pérez Andújar de discriminación territorial en la Barcelona de los 80 no difiere mucho de la descrita para los ghettos americanos (Wacquant 2007) o las banlieus francesas (Lapeyronie 2008), donde el lugar de residencia se convierte en un estigma per se. "Será difícil que a la gente joven de San Adrián les den trabajo fuera del barrio cuando dicen de dónde vienen" (2011: 114). Nunca antes, ni siquiera Candel, había narrado una oposición tan frontal entre el centro de Barcelona y los barrios periféricos, "la masa de bloques que rodea a Barcelona como los apaches rodean un fuerte" (ibid.: 33).

Sin pretender formular conclusiones sociológicas, Vázquez ofrece anécdotas personales que convergen en una idéntica oposición a la ciudad central. De adolescente, queda con dos amigos del colegio del OPUS para ir a Titus, una discoteca del centro de Badalona. "Cuando era pequeño soñaba con cumplir los dieciséis años para poder ir allí los sábados por la noche, ya que sabía que nadie de San Roque había conseguido traspasar sus puertas" (2013: 101). Pero le atenazaba el temor a ser rechazado, ya que "no poseía ni uno solo de los elementos que confirmaban el uniforme pijo de la época: no tenía ningún polo Lacoste, ni tampoco vaqueros Levi's ni zapatillas Nike». Aun así lo intenta porque "mi evolución personal pasaba por ser aceptado entre la gente bien de la ciudad". Una vez en la puerta de la discoteca, 
mi futuro en la ciudad se resolvería en menos de tres segundos. El de la puerta nos vio a los tres juntos: miró primero a Carlos, luego a Cesar y luego a mí, después miró a Carlos y a Cesar a la vez y luego nuevamente a mí. Y dictaminó:

-Vosotros entráis, él no.

Él era yo. (ibid:: 101)

Humillado, decidió regresar al barrio caminando.

Dejando atrás poco a poco el centro de la ciudad, atravesando zonas industriales repletas de fábricas de ladrillo negruzco para entrar al fin en San Roque, aquel conglomerado de bloques terribles que almacenaban almas envueltas en resignación. Como de costumbre, los dos bancos que había delante de mi bloque estaban ocupados por vecinas en bata que comían pipas a espuertas, y no sólo las saludé con una sonrisa por primera vez en mi vida, sino que me sentí más cercano a ellas que nunca (ibid.: 104-106).

\section{LA MURALLA CONSANGUÍNEA}

Barcelona para uno, Badalona para el otro, son grupos sociales rodeados de un muro infranqueable formado por lazos de parentesco impermeables. La exclusión de los barrios periféricos, habitados por gente de origen foráneo, está basada en la consanguineidad más estricta.

Frente a la imagen ampliamente extendida de Barcelona como una ciudad abierta y cosmopolita, para Pérez Andújar el parentesco opera como una frontera infranqueable que determina la pertenencia: "No hay manera de estar cerca de Barcelona si antes no lo estuvieron tus antepasados" (2011: 20). Más adelante, añade "Nadie pertenece a Barcelona por el mero hecho de vivir en ella, ni siquiera por haber nacido en la ciudad (....) Porque de Barcelona solo se es por familia y por dinero, en riguroso orden" (ibid.: 21). O bien, "la Sagrada Familia no formaba parte de nuestra familia" (ibid.: 20).

Para Pérez Andújar, la ciudad amurallada no es tanto la elite burguesa (como los migrantes de primera generación solían representar a "los catalanes") como la mesocracia de la clase media urbana, que mantiene al margen al "magma de cucarachas" que forma el extrarradio, a "la gente a la que de nada le sirve la familia para valerse, y eso mismo es lo que les impide ser de Barcelona" (ibid.: 89). Sorprende que en 2014 un jurado nombrado por Xavier Trias, alcalde convergente del Ayuntamiento de Barcelona, otorgara a Javier Pérez Andújar el premio Ciutat de Barcelona a los medios de comunicación por sus crónicas de la periferia metropolitana en El País. Es como si con el premio se le quisiera refutar su retórica.

Jorge Javier Vázquez también abunda en el papel excluyente del parentesco. Su padre intentaba por todos los medios que el hijo conquistara posiciones sociales que a él se le habían negado (de hecho para éste, nacido en Badalona, "vivir en San Roque había sido un retroceso"). Todos sus esfuerzos, como darle a su hijo una educación en escuelas privadas, habían ido destinados a que subiera en la escala social "O al menos recuperara el puesto que por derecho me pertenecía, el ser de la ciudad, formar parte de ella sin que jamás tuviera la sensación de que existía un mundo mejor al que por nacimiento no podía acceder" (2013: 72).

En 2010 Jorge Javier Vázquez ganó el premio Ondas al mejor presentador de televisión. En desacuerdo con el veredicto, los periodistas catalanes Carles Francino y 
Àngels Barceló, presentadores de la gala en el Liceo de Barcelona, se negaron a entregarle la estatuilla. En una entrevista que en 2013 le hace Albert Om para TV3, Vázquez rememora así ese momento: "el sentimiento que me inundó fue el de volver otra vez al mundo de San Roque (...) Aquello fue como decirme: '¿pero tú qué te pensabas, que te íbamos a dejar salir del barrio?". A lo que Albert Om le rebate: "Pero eso no tuvo nada que ver con Sant Roc. Yo creo que ellos protestaban por una forma de hacer televisión, independientemente que tu hubieses nacido en Sant Roc o en Taradell ${ }^{9}$. La réplica a esta objeción llega en una entrevista posterior que le hace Risto Mejide: "Cuando Francino y Barceló desaparecen del escenario para no entregarme el premio ¿hubieran hecho lo mismo con [Javier] Sardà si le hubieran premiado a él y no a Crónicas Marcianas? Jamás. Nunca lo hubieran hecho, ya te lo digo yo. Porque (...) Sardà pertenece a su casta y a un determinado grupo social de Barcelona ${ }^{10}$.

\section{ALEJAMIENTO Y RECONCILIACIÓN}

El yo autobiográfico no puede ser pensando como un sujeto estable y unitario, sino como dinámico y fragmentado. Como señalan Smith y Watson (2001: 1521-2), "at a given moment what calls itself the self is different from itself at any other given moment". $\mathrm{La}$ vida iba en serio y Paseos con mi madre mantienen una tensión entre la identificación y el alejamiento de los autores con respecto a sus orígenes sociales, pero ésta es una pugna interior que ambos autores ubican en marcos cronológicos diferentes. Si Vázquez va del alejamiento a la reconciliación, parece que Pérez Andújar toma el camino inverso.

Para Vázquez, salir con 25 años de su barrio natal para irse a vivir a Madrid ("mi ciudad, siempre lo había sido") es una liberación. En primer lugar porque Madrid le permite exteriorizar su sexualidad sin miedo a llevar la vergüenza a su familia. Pero también es una reubicación que le permite reconciliar su persona y su condición social, algo que no había podido hacer en Badalona. La vergüenza de su posición social (en Badalona decía que vivía cerca de los Bomberos "para evitar pronunciar el nombre de San Roque" (2013: 109) deriva en un resentimiento hacia sus propios progenitores. Reflexionando en retrospectiva, culpa a su familia por no haber sido reconocido como miembro pleno de la ciudad. "Porque gran parte de la culpa la tenían ellos, aquello estaba claro: vivir en San Roque no ayudaba, ni tampoco que mi madre viniera de Albacete y que mis abuelos paternos fueran de Murcia" (ibid.: 103). A diferencia de Pérez Andújar, Vázquez no exhibe un orgullo de clase obrera que le ayude a contrarrestar el estigma social. En su caso, reconocerse como "de barrio" se limita a una continua crítica al estilo "pijo" sin dejar por ello de avergonzarse de la propia condición. Pero al final del libro, desarrolla un reencuentro con sus orígenes sociales: "me he reconciliado con mis orígenes. Jamás volveré a ocultar que soy de San Roque y que en cincuenta metros cuadrados vivíamos cinco" (ibid.: 194), si bien no explica cómo ha obrado esta transformación. En La vida iba en serio, la reconciliación con el padre, que pasa de verdugo a víctima de sus propios prejuicios, va en paralelo al reconocimiento de sus orígenes sociales, que pasan a formar parte inalienable de su

\footnotetext{
${ }^{9}$ http://www.ccma.cat/tv3/alacarta/el-convidat/jorge-javier-vazquez/video/4695351/

${ }^{10}$ http://www.dailymotion.com/video/x28951e_jorge-javier-viajando-con-chester-charla-integra_tv
} 
identidad pública. Así, en la entrevista con Albert Om, Jorge Javier Vázquez querrá, después de mostrar su lujosa casa en una urbanización de Madrid, que una parte de la entrevista se grave delante del decrépito bloque de pisos de San Roque.

Aparentemente, Pérez Andújar hace el recorrido contrario. De una identificación total con su barrio de origen pasa a un progresivo alejamiento. Cuando deja su barrio natal para ir a vivir a Barcelona, se siente fuera de lugar, desubicado en el mundo cultural para el que trabaja ("qué pija es la cultura" (2011: 125) y en la ciudad. "Casi veinte años viviendo [en Barcelona] y sabiendo que ni uno de los pasos que he dado por sus aceras va a hacerme de esta ciudad" (ibid.: 14). Pero al tiempo también nos dice que deja de ir perteneciendo a su barrio de origen: "cada semana regreso a la periferia (....) en busca de una dosis de mí mismo (....) cuando llego a San Adrián ya no hay nada de lo que persigo. Son fantasmas". Los motivos de este alejamiento parecen tener que ver, al menos en parte, con el desencanto político, con el fin de la clase obrera como "clase para sí", con la conversión de los obreros en consumidores, con la pérdida de memoria e instinto defensivo al creer que ambulatorios, escuelas públicas y bocas de metro "las puso ahí la naturaleza" (ibid.: 59). La huelga general de 1988, donde participa en los piquetes de San Adrián, le sirve para entonar la "canción de despedida", el adiós a una época y a una idea de sí mismo. El adiós a la clase obrera (una prehistoria que agoniza, de la que ni siquiera quiero formar parte» (ibid: 167) se sustancia en otra de sus frases geniales: "Tantos años de luchas y de huelgas, para acabar viendo Intereconomía" (ibid:: 156).

Después de ese distanciamiento, Pérez Andújar pasa a personalizar cada vez más sus vínculos y su identidad. Viendo a su padre en el piquete señala: "yo me veo, antes que unido a una clase, unido a mi padre" (ibid.: 165), y sobre la cazadora que le legó su padre, añade: "se pertenece antes a una chaqueta que a una patria o a una clase" (ibid:: 166). Ni clase, ni patria, ni nación, ninguna identidad colectiva le queda ya que no sea la chaqueta de su padre o la voz de su madre.

Y entonces a cada rato mi madre me preguntará con sus ojos brillantes de inteligencia: ¿Sabes lo que es una devanaera? ¿Sabes lo que es un amolanchín? ¿Sabes lo que es un gordolobo? ¿Sabes lo que es una alloza? (...) Escucharé a mi madre paseando por el río Besós y atravesándola las llanuras secas de su voz anciana iré comprendiendo que no tengo más raíces que un puñado de palabras que apenas se usan, que ni siquiera soy de un idioma, que en realidad pertenezco a una voz" (Ibid.: 179).

\section{CONCLUSIONES: ¿VINDICANDO AL CHARNEGO?}

No, si por ello entendemos la reivindicación de una identidad colectiva de tipo étnico o nacional. Sí, como ejercicio de hacer pública una experiencia silenciada de segregación clasista. En Paseos con mi madre y La vida iba en serio, las expresiones "Cataluña" y "catalanes" están prácticamente ausentes, no es el tema, como sí lo es la ciudad central, palpable y dolorosamente concreta. En ambos relatos la oposición catalán/no catalán está subsumida en el antagonismo explícito entre estratos sociales localizados: los "pijos" del centro de la ciudad frente a los obreros de las "casas de cincuenta metros cuadrados" y los "bloques" periféricos. Aunque parecen dar por descontado que la mesocracia urbana es catalanohablante, lo cual sería matizable, al menos 
en el caso de Barcelona, el lenguaje de clase urbana prevalece sobre el lenguaje étnico o nacional. El efecto es paradójico. Por un lado, en el juego de metonimias (el espacio designa a la clase que a su vez designa al grupo étnico) se diluye la caracterización étnica del "otro" y del "yo". Es destacable que una fractura social tan contundente como la que se representa en estas autobiografías coincida con una divisoria étnica y que sin embargo ésta no se exprese en el lenguaje, lo que prolonga la "negación del conflicto étnico" que apuntaban Comas y Pujadas (1991: 51) sobre los barrios obreros de Tarragona. Pero por otro lado, se endurece el antagonismo social, aunque sea en el formato de una retórica hiperbólica. Al expresarse los contrastes sociales en términos de cercanías y distancias físicas, de lugares apropiados e inapropiados, la clase social aparece como espacialmente determinada, al tiempo que la exclusión espacial adopta la forma de un estricto parentesco consanguíneo. Con ello, las divisorias sociales se naturalizan y por tanto endurecen.

El cambio con respecto al discurso de los migrantes de primera generación recogido en los años 80 (Montes 1980; Solé 1982; Candel 1985; Botey 1986) es que entonces los migrantes recién llegados hablaban abiertamente de los "catalanes" como los "Otros", que además solían ser ricos y burgueses, pero también más cultos y avanzados. Ahora, en los casos analizados, el lenguaje se ha desetnicizado pero al mismo tiempo se ha hecho más hostil.

La nación desaparece del paisaje y en su lugar la ciudad asume la agencia de la exclusión. Pero la membresía urbana adquiere el formato racialista que tenía la catalanidad primigenia de antes de la guerra (Vandellós [1933] 2011). Podría decirse que el ius solis que la nación les otorgó a través de lo que López Bulla (1996: 172) llamaba el "decreto" de la catalanidad cívica del "es catalán todo el que viva y trabaje...", la ciudad clasista directamente accesible a la experiencia les quitó mediante la restitución del ius sanguinis.

Dada la total ausencia de estudios monográficos sobre las segundas y terceras generaciones de inmigrantes españoles, carecemos de información contextual suficiente que nos permita dilucidar hasta qué punto el discurso autobiográfico de Javier Pérez Andújar y Jorge Javier Vázquez es representativo de alguna tendencia, mayoritaria o no, en este sector de población. En todo caso, cabe destacar que los únicos relatos autobiográficos publicados hasta el momento por hijos de inmigrantes españoles crecidos en barrios segregados presentan, a pesar de sus numerosas diferencias formales, una representación de sí mismos como sujetos sociales que en muchos sentidos resulta bastante similar.

Por último, los relatos biográficos deben interpretarse como prácticas del presente. Todo relato autobiográfico tiene una pragmática, unos efectos prácticos que se construyen intersubjetivamente entre el autor (cuya intención suele ser implícita y solo parcialmente consciente) y el destinatario implícito (Smith y Watson 2001: 831). La pragmática o significado práctico del relato autobiográfico solo la podemos intuir a partir de indicios frágiles y elusivos. En este sentido, cabe notar que los libros analizados son una construcción del pasado que va acompañada de algunas quejas respecto al presente. El referido episodio de los premios Ondas le da una clara significación vindicativa a La Vida iba en serio. De modo no tan evidente, algo parecido ocurre con Javier Pérez Andújar cuando en Paseos con mi madre expresa una inespecífica irritación con el trato recibido por parte de la escena cultural de Barcelona. Ya se trate de resentimiento victimista, como estos 
relatos han sido a veces interpretados, o bien de la quiebra de un silencio resignado ante la injusticia, parece que la "condición charnega" también puede estar, para usar una de las expresiones favoritas del actual proceso soberanista, pasando pantalla. A qué paisajes conducirá, es más difícil de aventurar.

\section{BIBLIOGRAFÍA CITADA}

Alarcón, Amado. 2005. "Idiomas minoritarios e integración socioeconómica", en Carlota Solé, Antonio Izquierdo y Amado Alarcón (eds.), Integraciones diferenciadas: migraciones en Cataluña, Andalucía y Galicia: 314-334. Barcelona: Anthropos.

Barbal, Maria. 1999. Carrer Bolivia. Barcelona: Edicions 62.

Barrera, Andrés. 1985. La dialéctica de la identidad en Cataluña. Madrid: Centro de Investigaciones Sociológicas.

Botey, Jaume. 1986. Cinquanta-quatre relats d'immigració. Barcelona: Diputació de Barcelona.

Bourdieu, Pierre. 1988. La distinción. Criterio y bases sociales del gusto. Madrid, Taurus.

Candel, Francesc. 1964. Els altres catalans. Barcelona: Edicions 62.

Candel, Francesc. 1985. Els altres Catalans vint anys després. Barcelona: Edicions 62.

Cardoso, Roberto. 1995. "Identidade catalã e ideologia étnica". Mana 1(1): 13-44.

Clua, Montserrat. 2011. "Catalanes, inmigrantes y charnegos: 'raza', 'cultura' y 'mezcla' en el discurso nacionalista catalán. Revista de Antropología Social 20: 55-75.

Clua, Montserrat. 2014. "D'immigrants a ciutadans: la inclusion dels 'altres catalans' a la comunitat imaginada". Nous Horitzonts 207: 34-39.

Comas, Dolors y Joan Josep Pujadas. 1991. "Familias migrantes: reproducción de la identidad y del sentimiento de pertenencia". Papers 36: 33-56.

Conversi, Daniele. 1997. The Basques, the Catalans and Spain. Reno: University of Nevada Press.

Domingo, Andreu. 2014. Catalunya al mirall de la immigració. Barcelona: L'avenç.

Domingo, Andreu. 2015. "Immigració i imaginari social des de 1964: de la barreja a la interculturalitat", en Andreu Domingo (coord.), Recerca i Immigració VII. Migracions dels segles XX $i$ XXI: una mirada candeliana: 17-38. Barcelona: Generalitat de Catalunya.

Esteva, Claudio. 1973. "Aculturación y urbanización de inmigrados en Barcelona". Ethnica 5: 135-189.

Farràs, Andreu y Pere Cullell. 2009. L'ascensor. L'arribada al poder dels altres catalans. Barcelona: Angle.

Fernández, Miquel (coord.) 2009. Fabricar l'Immigrant. Aprofitaments politics de la immigració a Catalunya 1977-2009. Lleida: Pagès Editors.

Fernández, Miquel. 2006. "Immigrants per sempre?", en Lluis Cabrera, Marta Riera, Juan Miguel Portal, Pedro Morón, Bienve Moya, Miguel Fernández, Els altres andalusos: 395-461. Barcelona: La esfera de los libros.

Ferrándiz, Francisco. 2008. "Cries and Whispers: Exhuming and Narrating Defeat in Spain Today". Journal of Spanish Cultural Studies 9(2): 117-92.

Lapeyronnie, Didier. 2008. Ghetto urbain: ségrégation, volence, pauvreté en France aujourd'hui. París: Robert Laffont.

Levitt, Peggy y Waters, Mary (eds.) 2001. The Changing Face of Home. The Transnational Lives of Second Generation. Nueva York: Rusell Sage Foundation.

López, José. 1996. Cuando hice las maletas. Barcelona: Península.

Marín, Martí. (dir.) 2006. Memòries de viatge. 1940-1975. Sant Adrià del Bessos: Museu d'història de la immigració a Catalunya.

Marsé, Juan. 1966. Últimas tardes con Teresa. Barcelona: Seix Barral.

Marsé, Juan. 1970. La oscura historia de la prima Montse. Barcelona: Seix Barral.

Marsé, Juan. 1990. El amante bilingüe. Barcelona: Planeta.

Martínez, Guillem. 2001. "Charnego power", El País, 4 de enero.

Martínez, Guillem. 2002. "La perspectiva del charnego", El Pais, 2 de septiembre.

Miley, Thomas. 2006. Nacionalismo y política lingüística: el caso de Cataluña. Madrid: Centro de Estudios Políticos y Constitucionales. 
Molinero, Carme., y Pere Ysàs (eds.) 2010 Construint la ciutat democrática. Barcelona: Icària. Montes, Paco. 1980. Memorias andaluzas. Barcelona: Laia.

Narbona, Luis. 2014. "Barris de perifèria: por, oblit, conflicte". Nous Horitzonts 207: 58-63.

Noiriel, Gérard. 1988. Le creuset français: histoire de l'immigration XIXe-XXe siècle. Paris: Éditions du Seuil.

Pérez, Javier. 2011. Paseos con mi madre. Barcelona: Tusquets.

Pérez, Javier. 2013. "Charnegos: informe sobre un cadáver". Tinta Libre 3: 15-20

Portes, Alejandro y Rubén Rumbaut 2000. Legacies. The Story of the Immigrant Second Generation. Berkeley: University of California Press.

Porzio, Laura. 2012. "El cuerpo entre la resistencia y la asimilación: Estrategias incorporadas e itinerario corporal de un Latin King". Revista de Dialectología y tradiciones populares 77(1): 85-114.

Prat, Joan. 2007. "En busca del paraíso. Historias de vida y migración". Revista de dialectologia y tradiciones Populares 62(2): 21-61.

Pujadas, Joan Josep. 2014. "La ciutat amagada: ciutadans amagats, barris oblidats". Nous Horitzonts 207: 40-45.

Pujol, Jordi. 1976. Immigració: problema i esperança de Catalunya. Barcelona: Nova Terra.

Puntí, Jordi. 2011. Els castellans. Barcelona: L’Avenç.

Quinby, Lee. 1992. "The Subject of Memoirs", en Sidonie Smith y Julia Watson (eds), De/Colonizing the Subject. The Politics of Gender in Women's Autobiography: 297-320. Minneapolis: University of Minnesota Press.

Rodrigo, Javier. 2006. "La Guerra Civil: Memoria, olvido, recuperación e instrumentalización”. Hispania Nova, 6: 1-20.

Shafir, Gershon. 1995. Immigrants and nationalists. Nueva York: State University of New York Press.

Smith, Sidonie y Julia Watson. 2001. Reading Autobiography: A Guide for Interpreting Life Narratives. Minneapolis: University of Minessota Press.

Solé, Carlota. 1982. Los inmigrantes en la sociedad y la cultura catalanas. Barcelona: Edicions 62.

Solé, Carlota. 1981. La integración sociocultural de los inmigrantes en Cataluña. Madrid: Centro de Investigaciones Sociológicas.

Simmel, Georg. 2012 [1908]. "El extranjero", George Simmel El extranjero. Madrid: Ediciones Sequitur.

Subirats, Marina. 2012. Barcelona: de la necessitat a la llibertat. Le classes socials al tombant del segle XXI. Barcelona: L'Avenç.

Torres, Maruja. 1998. Un calor tan cercano. Barcelona: Alfaguara.

Vandellós, Josep. [1933] 2011. La inmigración en Cataluña. Madrid: Centro de Investigaciones Sociológicas.

Vázquez, Jorge. 2013. La vida iba en serio. Barcelona: Planeta.

Vázquez Montalbán, Manuel. 1987. Los alegres muchachos de Atzavara. Barcelona: Seix Barral.

Vilarós, Teresa. 2003. "The Passing of the Xarnego-Immigrant: Post-Nationalism and the Ideologies of Assimilation in Catalonia". Arizona Journal of Hispanic Cultural Studies 7: 231-248.

Wacquant, Loïc. 2007. "Territorial Stigmatization in the Age of Advanced Marginality". Thesis Eleven 91(1): $66-77$.

\section{FILMOGRAFÍA}

Bigas Luna, Josep Juan (Director). 2006. Yo soy la Juani. Media Films (Productora).

Corbacho, José y Juan Cruz (Dirs.). 2005. Tapas. Tusitala/Castelao Productions.

Forn, Josep M. (Dir.). 1968. La piel quemada. P.C. Teide (Productora).

Robira-Beleta, Francesc (Dir.). 1963. Los tarantos. Tecisa/Films Rovira-Beleta (Productora).

Fecha de recepción: 3 de diciembre de 2015

Fecha de aprobación: 23 de marzo de 2016 